\title{
Reduction of HbA1c levels following nonsurgical treatment of periodontal disease in type 2 diabetics
}

\author{
José M$^{\text {a }}$ Montoya-Carralero ${ }^{1}$, Manuel Saura-Pérez ${ }^{2}$, Manuel Canteras-Jordana ${ }^{3}$, Isabel M $^{\text {a }}$ Morata-Murcia $^{4}$
}

${ }^{1}$ DDS, PhD. University specialist in Periodontology. Master in integrated dental care: Implantology. University of Murcia (Spain)

${ }^{2} \mathrm{MD}, \mathrm{PhD}$. Specialist in Stomatology. Primary Care dental physician. Murcia Health Service. Associate Professor of Gerodontology and Periodontology. University of Murcia (Spain)

${ }^{3}$ Chairman of Biostatistics. University of Murcia (Spain)

${ }^{4}$ DDS. Master in Orthodontics. Mississippi University Institution (Spain)

Correspondence:

C/ Alhambra 5-5A

30204 - Cartagena

Spain

icuect@hotmail.com

Received: 11/08/2009 Accepted: 21/02/2010
Montoya-Carralero JM, Saura-Pérez M, Canteras-Jordana M, MorataMurcia IM. Reduction of HbAlc levels following nonsurgical treatment of periodontal disease in type 2 diabetics. Med Oral Patol Oral Cir Bucal. 2010 Sep 1;15 (5):e808-12.

http://www.medicinaoral.com/medoralfree01/v15i5/medoralv15i5p808.pdf

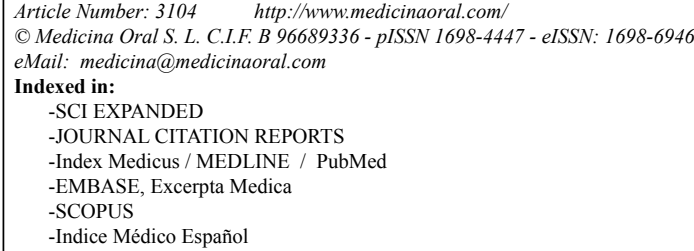

\begin{abstract}
Objectives: A study was made of the effect of nonsurgical periodontal treatment upon blood glucose control in type 2 diabetics with periodontal disease.

Study design: A pre-post repeated measures analytical design was used, with a PubMed search of the related articles published up until December 2008.

Results: The improvement in glycosylated hemoglobin (HbA1c) after nonsurgical periodontal treatment on comparing the baseline $(8.0290 \pm 1.5539)$ and final values $(7.7806 \pm 1.5636)$ was $0.2483 \pm 0.1171$, and proved statistically significant $(\mathrm{p}=0.042)$.

Conclusions: A decrease in HbAlc was observed after treatment, thus indicating improved blood glucose control in type 2 diabetics with periodontal disease.
\end{abstract}

Key words: Type 2 diabetes, HbAlc, periodontal disease, periodontitis.

\section{Introduction}

Diabetes mellitus and periodontal disease are two highly prevalent chronic disorders.

Metabolic control of blood glucose and the prevention and/or treatment of the macro- and microvascular complications of diabetes are the main reason leading diabetics to seek medical care very frequently in both primary care and in specialized centers.
Authors such as Li et al. (1), Amar et al. (2), Teng et al. (3) and Kinane et al. (4) have related periodontal disease to systemic disorders or problems such as respiratory dysfunction, cardiovascular disease, low weight at birth, osteoporosis or diabetes mellitus.

The relationship between diabetes and periodontal disease has been the subject of many studies. In this sense, there is increasing agreement that diabetes and peri- 
odontal disease exhibit a bidirectional relationship. In 1993, Löe (5) described periodontal disease as the sixth complication of diabetes, after diabetic nephropathy, neuropathy, retinopathy, vascular disease and delayed healing. Soskolne et al. (6) in turn indicate that according to data from the United States Department of Health and Human Services (1996), derived from a National Health and Nutrition Examination Survey (NHANES III), not only does epidemiological evidence indicate that periodontitis is more common in diabetic patients, but the prevalence of diabetes in patients with periodontitis is moreover significantly greater than in individuals without periodontal problems.

Many studies have found diabetes to be associated with an increased prevalence and progression of periodontal disease. Other authors in turn have shown periodontal disease to be correlated to poorer blood glucose control in diabetic individuals, and to an increased risk of suffering complications of diabetes.

Diabetes treatment aims to keep blood glucose within the recommended limits, and in this sense the presence of periodontitis affects blood glucose control.

The present study was carried out to evaluate the effect of nonsurgical periodontal treatment upon blood glucose control in type 2 diabetics with periodontal disease.

\section{Material and Method}

The present study comprised a pre-post repeated measures analytical design, with a PubMed search of the related articles published up until December 2008.

The study sample consisted of 31 patients: 11 males $(35.5 \%)$ and 20 females (64.5\%), with an age range of 42-81 years (mean: $66.06 \% \pm 8.73$ ).

The inclusion criteria were: type 2 diabetes mellitus, inclusion in the diabetes program of the Murcia Health Service (Spain), age over 18 years, the absence of cognitive impairment and previous periodontal treatment, willingness to undergo exploration and the required complementary tests, and the signing of informed consent. We excluded patients receiving antibiotic treatment or who had received such treatment in the previous month, pregnant women, fully edentulous patients and type 1 diabetics.

Data collection and exploration of the oral cavity were carried out by the same dentist. In all cases a detailed case history was compiled, including patient age, sex, disease antecedents, type of diabetes, current treatment, duration of the disease in years, and associated systemic disorders. A clinical examination of the oral cavity was carried out, evaluating the condition of the oral mucosa, the Silness and Löe plaque index, and the community periodontal index (CPI). As complementary tests, all patients were subjected to a panoramic X-ray study and to the determination of glycosylated hemoglobin levels (HbAlc).

All 31 patients presented periodontal pouches in some of the explored sextants. In all cases nonsurgical periodontal treatment was carried out, with the extraction of those teeth showing excessive mobility or caries-induced destruction not amenable to conservative dental management.

Treatment was completed in several sessions (Table 1), according to the needs of each individual patient, with an interval of 7 days between sessions.

Tartar removal was carried out in a first session, and instructions were provided on correct tooth brushing and the use of interproximal brushes (Interprox ${ }^{\circledR}$, Dentaid, Spain) and dental floss. In addition, $0.12 \%$ clorhexidine digluconate rinses were prescribed (every 12 hours for 15 days).

Seven days after tartar removal, the scaling and root planing sessions were started in combination with ultrasound under local anesthesia (3\% mepivacaine or $4 \%$ articaine), for a total of $1-4$ sessions, depending on the number of affected quadrants. Whenever possible, two quadrants per session were completed. Following scaling and root planning, the periodontal pouches were irrigated with $0.12 \%$ clorhexidine digluconate using a fine-needled syringe.

Approximately 30 days after the last periodontal treatment session, clinical examination of the oral cavity was again carried out, evaluating the condition of the oral mucosa, the Silness and Löe plaque index, CPI and HbAlc.

A descriptive analysis was made of each study variable, recording the corresponding distribution of frequencies. The basic parameters were calculated in the case of quantitative variables, i.e., mean, median, quartiles, and minimum and maximum.

Pre- and post-treatment comparisons of means were

Table 1. Treatment scheme.

\begin{tabular}{|l|l|l|l|}
\hline \multicolumn{1}{|c|}{ First visit } & \multicolumn{1}{|c|}{ Treatment phase } & \multicolumn{1}{c|}{ 30 days } & \multicolumn{1}{c|}{ Control } \\
\hline Anamnesis & Instructions on hygiene & & Final exploration \\
First exploration & Tartar removal & & HbAlc \\
Panoramic X-ray study & Scaling and root planing & & \\
HbAlc & Extractions & & \\
\hline
\end{tabular}


made with the Student t-test for paired data. The comparison of means for several groups was based on analysis of variance (ANOVA), complemented by mean pair equality contrasting using the minimum significant difference method with Bonferroni correction.

The comparison of proportions and the association or relationship between qualitative variables in turn was based on the analysis of contingency tables and the Pearson chi-squared test, complemented by analysis of residues.

The relationship between quantitative variables was explored by regression / correlation analysis, calculating the Pearson linear correlation coefficient.

\section{Results}

Approximately one-half of the patient series had diabetes diagnosed 8 or more years ago, and about $25 \%$ had been diagnosed with the disease 20 or more years ago. The mean duration of the disease was $11.03 \pm 7.86$ years. A statistically significant correlation $(p=0.002)$ was found between the HbA1c levels both at the start and end of the study, and the duration of diabetes, i.e., the longer the duration of the disease, the poorer blood glucose control, since the HbAlc levels were seen to increase.

Most of the patients $(71 \%)$ were being treated with oral antidiabetic drugs, and $25.8 \%$ of the series required the administration of insulin to secure metabolic control. In only a small proportion of cases $(3.2 \%)$ was management limited to dietary measures and physical exercise. Significant differences were observed in the initial $(p=0.046)$ and final HbAlc levels $(p=0.036)$ between the subjects receiving different types of treatment for diabetes. Of the 31 patients included in the study, a single patient was well controlled by dietary measures and physical exercise only $(\mathrm{HbAlc}=6.5 \%) ; 8$ were receiving insulin, with a mean HbAlc of $9.1 \%$; and the remaining 22 patients were treated with oral antidiabetic agents and presented a mean $\mathrm{HbAlc}$ of $7.7 \%$.

As regards associated disease, the most common disorder was arterial hypertension (in $80.6 \%$ of all subjects), followed by osteoarthritis (25.8\%), hypercholesterolemia $(19.4 \%)$, osteoporosis $(12.9 \%)$, stroke $(9.7 \%)$, retinopathy $(6.5 \%)$, acute myocardial infarction $(6.5 \%)$ and chronic obstructive pulmonary disease (3.2\%). Only $6.5 \%$ of the patients had no associated diseases.

Exploration of the oral cavity showed most patients (71\%) to have disease-free oral mucosas. The most frequent mucosal lesion was lichen planus (6.5\% of the series).

The initial mean plaque index was $1.6368 \pm 0.788$, and was seen to decrease significantly to $0.7907 \pm 0.619$ after periodontal treatment $(\mathrm{p}=0.0005)$.

On processing the scores of the CPI, a component of the community periodontal index of treatment needs (CPITN), as quantitative variables, a mean value of $3.16 \pm 0.37$ was obtained for maximum CPI (defined as the maximum CPI score obtained in any of the explored sextants in each case) at initial exploration. Following periodontal treatment, a significant decrease was observed $(p=0.005)$, since the mean maximum CPI after treatment was $1.97 \pm 1.25$. In order to assess improvement of this parameter, the above data were used to generate a healing index, i.e., reflecting the cases that evolved towards scores not indicative of periodontitis $(0,1$ or 2$)$ at final exploration, and an improvement index, reflecting the cases that evolved towards comparatively lower scores:

Healing index $=$ number of cases evolving towards scores indicating no periodontitis / total number of cases $x 100=14 / 31=45.16 \pm 17.52 \%$.

Improvement index $=$ number of cases evolving towards comparatively lower scores / total number of cases x 100 $=18 / 31=58.06 \pm 17.37 \%$.

The observed improvement (Table 2) from the initial or baseline $(8.0290 \pm 1.5539)$ to the final HbAlc values (7.7806 \pm 1.5636$)$ was $0.2483 \pm 0.1171$, and proved statistically significant $(\mathrm{p}=0.042)$. The correlation coefficient of $0.913(p=0.0005)$ between mean initial and final $\mathrm{HbAlc}$ shows the final values to be dependent upon the baseline values, i.e., a patient starting with low HbAlc values improved to the same degree as a patient starting from higher values.

We observed no significant relationship between the initial maximum CPI score and the baseline HbAlc value. However, a correlation was observed between the final maximum CPI and the final HbAlc value $(p=0.041)$, i.e., higher CPI scores were associated with higher HbAlc levels at the end of the study.

Table 2. Reduction of HbAlc levels.

\begin{tabular}{|c|c|c|c|c|c|c|c|c|}
\hline & \multirow[b]{2}{*}{ Mean } & \multirow[b]{2}{*}{ St. dev. } & \multirow[b]{2}{*}{$\begin{array}{l}\text { St. error } \\
\text { of mean }\end{array}$} & \multicolumn{2}{|c|}{$\begin{array}{l}95 \% \text { confidence inter- } \\
\text { val for the difference }\end{array}$} & \multirow[b]{2}{*}{$\mathbf{T}$} & \multirow[b]{2}{*}{ df } & \multirow[b]{2}{*}{ Sig. (two-sided) } \\
\hline & & & & Lower & Upper & & & \\
\hline $\begin{array}{l}\text { Initial HbA1c - Final } \\
\text { HbAlc }\end{array}$ & 0.24839 & 0.65211 & 0.11712 & 0.00919 & 0.48758 & 2.121 & 30 & 0.042 \\
\hline
\end{tabular}




\section{Discussion}

Diabetes mellitus and periodontal disease are two highly prevalent chronic disorders both in Spain and elsewhere. Although many studies have examined the bidirectional relationship between diabetes and oral disease, and the effects of periodontal treatment upon the metabolic control of diabetes, the great diversity of screening criteria, designs, durations of follow-up, types of patients or treatment protocols involved makes it difficult to establish comparisons.

In effect, most studies show great variability in the duration of follow-up. HbAlc estimates the mean blood glucose levels in the previous 30-90 days. The period between initial HbAlc recorded on the first visit and final $\mathrm{HbAlc}$ recorded on the post-treatment control visit falls within this time interval, since according to the study protocol the first treatment varied between 3-5 weeks after the first visit, and 30 days after the last scaling and root planing session a control was programmed and the final HbAlc value was registered. Other authors such as Faria-Almeida et al. (7), Navarro et al. (8) and Grossi et al. (9) recorded final HbAlc 3 and 6 months after treatment, while Rodrigues et al. (10), Promsudthi et al. (11) and Cruz et al. (12) recorded this parameter 3 months after the initial HbAlc value. In turn, O'Connell et al. (13) and Kiran et al. (14) obtained the value 3 months after treatment, while Al-Mubarak et al. (15) did so 2 months after therapy, Iwamoto et al. (16) one month after treatment, and Stewart et al. (17) recorded final HbAlc 10 months after the initial or baseline HbAlc value.

As regards the observed significant differences in both the initial and final HbAlc values depending on the type of diabetes treatment received, we consider such differences to be logical, since patients subjected only to dietary management and physical exercise tend to be individuals that maintain good blood glucose control without the need for medication. In contrast, type 2 diabetics treated with oral antidiabetic drugs are not controlled or present HbAlc values that are not close to the levels indicating metabolic control of the disease, and moreover tend to vary treatment and receive insulin therapy. However, the recorded improvement in HbAlc levels was independent of the type of treatment received for diabetes, and may be regarded as independent of the latter.

The treatment provided in our patient series improved the clinical parameters, and thus also oral health. All the subjects had periodontitis at the start of the study. Most of them (83.9\%) presented a maximum CPI score of 3, while the rest had a score of 4. Periodontal status improved as a result of treatment, since 6 patients presented a maximum CPI score of 0 , and $45.2 \%$ had no sextant with scores indicative of periodontitis. Among the subjects that continued to present periodontitis after treatment, none had a maximum CPI score of 4. The periodontitis healing and improvement indexes used in the statistical analysis were $45.16 \pm 17.52 \%$ and $58.06 \pm 17.37 \%$, respectively. The improvement between initial and final CPI score was statistically significant $(p=0.005)$, in the same way as the improvement between the initial and final plaque index value $(p=0.0005)$.

The hypothesis that HbAlc decreases after periodontal treatment in diabetic individuals with periodontitis has been the subject of many studies, with variable results. In our series there were statistically significant differences $(p=0.042)$ between the initial and final HbAlc values after the treatment provided, with a decrease in HbAlc level and thus improved metabolic control of blood glucose. The observed correlation coefficient of $0.913(\mathrm{p}=0.0005)$ between mean initial and final HbA1c shows the final values to be dependent upon the baseline values, i.e., a patient starting with low HbAlc values improved to the same degree as a patient starting from higher values. Similar data in relation to reductions in HbAlc have been published by other authors (7-10, 1319), though many investigators have recorded no such differences in similar studies.

Among the trials reporting reductions in HbAlc, we have found studies that use antibiotics (fundamentally local minocycline or systemic doxycycline), together with periodontal treatment $(9,13,16,19)$. Other authors such as Promsudthi et al. who likewise used antibiotic treatment, failed to obtain satisfactory results (11). In contrast, Rodrigues et al. (10) reported good results but in the group not administered antibiotics. The rest of the studies in the reviewed literature reporting such metabolic improvements did not use antibiotic treatment. Thus, the role of antibiotics in reducing HbAlc does not seem quite clear, since similar results appear to be achieved with periodontal treatment in the absence of antibiotics. Nevertheless, most studies that use antibiotic treatment report significant results.

Based on the maximum CPI score for diagnosing the cases of periodontitis, we found that at baseline (i.e., before starting periodontal treatment), all the patients had periodontal pouches. Under these circumstances, no correlation to the initial HbAlc levels was observed. However, after treatment some patients continued to have periodontitis while others did not. Under these circumstances a positive correlation was found between the final maximum CPI scores and HbAlc levels, i.e., higher CPI scores were associated with higher HbAlc levels at the end of the study. Similar results have been published by other authors (20). In our opinion, the initial situation in which all patients had periodontal pouches did not allow us to identify this correlation. Lastly, on contrasting the improvement in maximum CPI score with the improvement in HbA1c levels after treatment, the mentioned correlation disappeared - thus indicating that improvement occurred in all cases regardless of the degree of periodontal involvement. 


\section{Conclusions}

The following conclusions can be drawn from the present study:

1. The HbA1c levels are correlated to the duration of the disease and to the type of treatment provided for type 2 diabetes mellitus.

2. The HbAlc levels are correlated to periodontal health status after treatment in type 2 diabetics.

3. Following nonsurgical periodontal treatment, a decrease in HbAlc is observed, thus indicating improved blood glucose control in type 2 diabetics.

4. Improvement in the HbAlc levels is obtained regardless of the duration of the disease and the treatment provided for type 2 diabetes mellitus.

5. Improvement in the HbAlc levels of type 2 diabetics after periodontal treatment is obtained regardless of the degree of periodontal involvement at baseline.

\section{References}

1. Li X, Kolltveit KM, Tronstad L, Olsen I. Systemic diseases caused by oral infection. Clin Microbiol Rev. 2000;13:547-58.

2. Amar S, Han X. The impact of periodontal infection on systemic diseases. Med Sci Monit. 2003;9:RA291-9.

3. Teng YT, Taylor GW, Scannapieco F, Kinane DF, Curtis M, Beck JD, et al. Periodontal health and systemic disorders. J Can Dent Assoc. 2002;68:188-92.

4. Kinane D, Bouchard P; Group E of European Workshop on Periodontology. Periodontal diseases and health: Consensus Report of the Sixth European Workshop on Periodontology. J Clin Periodontol. 2008;35:333-7.

5. Löe H. Periodontal disease. The sixth complication of diabetes mellitus. Diabetes Care. 1993;16:329-34.

6. Soskolne WA, Klinger A. The relationship between periodontal diseases and diabetes: an overview. Ann Periodontol. 2001;6:91-8.

7. Faria-Almeida R, Navarro A, Bascones A. Clinical and metabolic changes after conventional treatment of type 2 diabetic patients with chronic periodontitis. J Periodontol. 2006;77:591-8.

8. Navarro-Sanchez AB, Faria-Almeida R, Bascones-Martinez A. Effect of non-surgical periodontal therapy on clinical and immunological response and glycaemic control in type 2 diabetic patients with moderate periodontitis. J Clin Periodontol. 2007;34:835-43.

9. Grossi SG, Skrepcinski FB, DeCaro T, Robertson DC, Ho AW, Dunford RG, et al. Treatment of periodontal disease in diabetics reduces glycated hemoglobin. J Periodontol. 1997;68:713-9.

10. Rodrigues DC, Taba MJ, Novaes AB, Souza SL, Grisi MF. Effect of non-surgical periodontal therapy on glycemic control in patients with type 2 diabetes mellitus. J Periodontol. 2003;74:1361-7.

11. Promsudthi A, Pimapansri S, Deerochanawong C, Kanchanavasita $\mathrm{W}$. The effect of periodontal therapy on uncontrolled type 2 diabetes mellitus in older subjects. Oral Dis. 2005;11:293-8.

12. Da Cruz GA, de Toledo S, Sallum EA, Sallum AW, Ambrosano GM, de Cássia Orlandi Sardi J, et al. Clinical and laboratory evaluations of non-surgical periodontal treatment in subjects with diabetes mellitus. J Periodontol. 2008;79:1150-7.

13. O'Connell PA, Taba M, Nomizo A, Foss Freitas MC, Suaid FA, Uyemura SA, et al. Effects of periodontal therapy on glycemic control and inflammatory markers. J Periodontol. 2008;79:774-83.

14. Kiran M, Arpak N, Unsal E, Erdoğan MF. The effect of improved periodontal health on metabolic control in type 2 diabetes mellitus. J Clin Periodontol. 2005;32:266-72.

15. Al-Mubarak S, Ciancio S, Aljada A, Mohanty P, Ross C, Dandona $P$. Comparative evaluation of adjunctive oral irrigation in diabetics. J Clin Periodontol. 2002;29:295-300.
16. Iwamoto Y, Nishimura F, Nakagawa M, Sugimoto H, Shikata K, Makino $\mathrm{H}$, et al. The effect of antimicrobial periodontal treatment on circulating tumor necrosis factor-alpha and glycated hemoglobin level in patients with type 2 diabetes. J Periodontol. 2001;72:774-8. 17. Stewart JE, Wager KA, Friedlander AH, Zadeh HH. The effect of periodontal treatment on glycemic control in patients with type 2 diabetes mellitus. J Clin Periodontol. 2001;28:306-10.

18. Schara R, Medvescek M, Skaleric U. Periodontal disease and diabetes metabolic control: a full-mouth disinfection approach. J Int Acad Periodontol. 2006;8:61-6.

19. Skaleric U, Schara R, Medvescek M, Hanlon A, Doherty F, Lessem J. Periodontal treatment by Arestin and its effects on glycemic control in type 1 diabetes patients. J Int Acad Periodontol. 2004;6:160-5.

20. Silvestre FJ, Miralles L, Llambes F, Bautista D, Solá-Izquierdo E, Hernández-Mijares A. Type 1 diabetes mellitus and periodontal disease: relationship to different clinical variables. Med Oral Patol Oral Cir Bucal. 2009;14:E175-9. 